\title{
Long-term stability of a non-adapted aerobic granular sludge process treating fish canning wastewater associated to EPS producers in the core microbiome
}

\author{
Ana M.S. Paulo ${ }^{\mathrm{a}, *}$, Catarina L. Amorim ${ }^{\mathrm{a}}$, Joana Costa ${ }^{\mathrm{b}}$, Daniela P. Mesquita ${ }^{\mathrm{b}}$, \\ Eugénio C. Ferreira $^{\mathrm{b}}$, Paula M.L. Castro ${ }^{\mathrm{a}}$

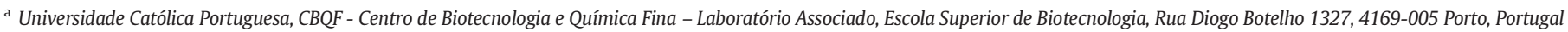 \\ ${ }^{b}$ Centre of Biological Engineering, Universidade do Minho, Campus de Gualtar, 4710-057 Braga, Portugal
}

\section{H I G H L I G H T S}

- Non-acclimated aerobic granules can treat fish canning wastewater with variable composition.

- Carbon and nitrogen loads were the main disturbance factors.

- Main microbial community changes occurred during higher organic load period.

- Bacterial groups associated to EPS production, carbon and nutrients removal were resilient.

- Microbiome diversity and adaptation supported AGS long-term stability.

\section{A R T I C L E I N F O}

\section{Article history:}

Received 11 August 2020

Received in revised form 22 October 2020

Accepted 15 November 2020

Available online 21 November 2020

Editor: Paola Verlicchi

\section{Keywords:}

AGS

Food industry wastewater

Organic load

Salt

Bacterial community

\section{GRAPHICALA B S T R A C T}

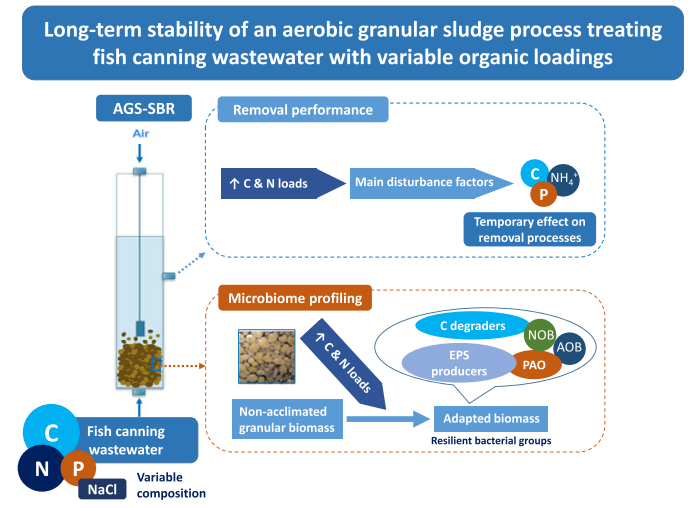

\begin{abstract}
A B S T R A C T
The tolerance of aerobic granular sludge (AGS) to variable wastewater composition is perceived as one of its greatest advantages compared to other aerobic processes. However, research studies select optimal operational conditions for evaluating AGS performance, such as the use of pre-adapted biomass and the control of wastewater composition. In this study, non-adapted granular sludge was used to treat fish canning wastewater presenting highly variable organic, nutrient and salt levels over a period of ca. 8 months. Despite salt levels up to $14 \mathrm{~g} \mathrm{NaCl}$ $\mathrm{L}^{-1}$, the organic loading rate (OLR) was found to be the main factor driving AGS performance. Throughout the first months of operation, the OLR was generally lower than $1.2 \mathrm{~kg} \mathrm{COD} \mathrm{m}^{-3} \mathrm{day}^{-1}$, resulting in stable nitrification and low COD and phosphorous levels at the outlet. An increase in OLR up to $2.3 \mathrm{~kg}$ COD m${ }^{-3} \mathrm{day}^{-1}$ disturbed nitrification and COD and phosphate removal, but a decrease to average values between 1 and $1.6 \mathrm{~kg} \mathrm{COD} \mathrm{m}^{-3}$ day $^{-1}$ led to resuming of those processes. Most of the bacteria present in the AGS core microbiome were associated to extracellular polymeric substances (EPS) production, such as Thauera and Paracoccus, which increased during the higher OLR period. Ammonium-oxidizing bacteria (AOB) and nitrite-oxidizing bacteria (NOB) species were detected in AGS biomass; while AOB were identified throughout the operation, NOB were no further identified after the period of increased OLR. Different polyphosphate-accumulating organisms (PAOs) were detected along the process: Candidatus Accumulibacter, Tetrasphaera and Gemmatimonas. A non-adapted granular sludge was able to treat the fish canning wastewater and to tolerate salinity fluctuations up to $14 \mathrm{~g} \mathrm{~L}^{-1}$. Overall, a high microbial diversity associated to EPS producers allowed to preserve bacterial groups responsible for nutrients removal, contributing to the adaptation and long-term stability of the AGS system.
\end{abstract}

(c) 2020 Elsevier B.V. All rights reserved.

\footnotetext{
* Corresponding author.

E-mail addresses: apaulo@porto.ucp.pt (A.M.S. Paulo), camorim@porto.ucp.pt (C.L. Amorim), joana.costa@ceb.uminho.pt (J. Costa), daniela@deb.uminho.pt (D.P. Mesquita), ecferreira@deb.uminho.pt (E.C. Ferreira), plcastro@porto.ucp.pt (P.M.L. Castro).
} 


\section{Introduction}

Aerobic granular sludge (AGS) is an eco-innovative technology with several advantages compared to activated sludge systems, such as smaller footprint, reduced energy demand and quicker sludge settling (Guo et al., 2020). AGS is formed by self-immobilized microorganisms, distributed in spherical layered structures, where aerobic and anoxic microbes co-exist, allowing for the removal of carbon, nitrogen and phosphorous in a single reactor (Rollemberg et al., 2018; Winkler et al., 2018). AGS is composed of extracellular polymeric substances (EPS) which, together with granules structure, are also relevant for the protection of bacteria towards stress scenarios, increasing granules tolerance to toxic substrates and resistance to variable wastewater composition (Amorim et al., 2017). All these advantages have resulted in the widespread of the AGS technology at full-scale wastewater plants (Guo et al., 2020). However, the stability of granular sludge facing variable organic loads or the presence of toxics in the wastewater is still poorly reported, crucial when dealing with industrial wastewater (Carrera et al., 2019). The success of the AGS process depends on a high diversity of bacterial groups for performing carbon and nutrients removal, also involved in granule formation and stability (Weissbrodt et al., 2014; Xia et al., 2018). AGS processes rely on the balance between polyphosphateaccumulating organisms (PAOs), ammonium-oxidizing bacteria (AOB) and nitrite-oxidizing bacteria (NOB) and fast-growing microorganisms, with ability for hydrolysis, denitrification and EPS production (Szabó et al., 2017; Xia et al., 2018). These processes are highly dependent on the type of wastewater (Layer et al., 2019; Rollemberg et al., 2018) and on the organic load, more than on the reactor operational conditions (Pishgar et al., 2019).

To date, most of the studies on AGS performance and microbial community dynamics during the treatment of wastewater with variable composition or organic load were mainly performed under controlled conditions, using synthetic wastewater (Hamza et al., 2019; He et al., 2020). Although giving valuable insights on the AGS technology, its applicability for the treatment of real wastewater is still largely unreported. The fish canning industry produces wastewater with variable composition in organic matter, nitrogen and phosphorous, and salt from the brining process, resulting in a diversity of factors affecting the biological treatment. In the past, the combination of anaerobic and aerobic processes for treating fish processing wastewater has been considered an optimal solution, using the anaerobic process as a pretreatment (Chowdhury et al., 2010). Carmen et al. (2013) proposed a nitrifying/denitrifying system for treating an effluent from an anaerobic digester treating fish canning wastewater. However, the amount of oil and grease present in this type of wastewater can easily compromise its biodegradability (Cristovão et al., 2015), resulting in the need of other pre-treatments to separate fat from the wastewater. Previous studies focused on AGS performance and granules stability treating fish canning wastewater with a very high salinity (Corsino et al., 2016; Corsino et al., 2017) have shown that the AGS process can be quite stable at salt concentrations up to $50 \mathrm{~g} \mathrm{~L}^{-1}$. Carrera et al. (2019) investigated the effect of different feeding strategies using an AGS process to treat fish canning wastewater, reporting that the anaerobic feeding phase might not be beneficial for the long-term stability of the AGS. These latter studies performed granulation of suspended biomass, either adapted to high salt concentration or to the fish canning wastewater, for treating sequential batches of wastewater with stable composition. The main objective of the present work was to investigate if granular sludge adapted to urban wastewater was able to treat fish canning wastewater with variable organic load and salinity, without the need for biomass adaptation and/or granulation. To simulate wastewater variations associated to fluctuations in the fish canning production processes, the wastewater composition was not controlled, resulting in variable carbon, nutrients and salt concentrations within different operational phases. A lab-scale AGS-SBR (sequencing batch reactor) operated for 231 days served as a basis for the study. Both AGS performance and microbiome composition were evaluated throughout the operation, to get a deeper insight on how variability in wastewater quality can influence the performance and the evolution of the microbial community in response to those changes, which will give a more complete overview on the AGS application in this industrial sector, by broadening the range of solutions.

\section{Material and methods}

\subsection{AGS setup and operation}

A lab-scale SBR with a working volume of $2.5 \mathrm{~L}$ was operated in four successive treatments of $6 \mathrm{~h}$ cycles per day, with $60 \mathrm{~min}$ of anaerobic feeding, $292 \mathrm{~min}$ of aeration, $3 \mathrm{~min}$ of settling and $5 \mathrm{~min}$ of effluent withdrawal. The reactor was operated at a volumetric exchange ratio (VER) of 40\%. The Sludge Retention Time (SRT) was not controlled over the operational period. The system was operated in cycles using an automatic timer (Siemens Logo! 230RC) to start and stop pumps for influent, aeration and effluent withdrawal. Aeration was provided at the bottom of the reactor ( $4 \mathrm{~L} \mathrm{~min}^{-1}$; superficial air velocity of $84.8 \mathrm{~m} \mathrm{~h}^{-1}$ ). The initial MLVSS (mixed liquor volatile suspended solids) was ca. $10 \mathrm{~g} \mathrm{VSS} \mathrm{L}^{-1}$. AGS from a reactor located in Frielas wastewater treatment plant (WWTP), Lisbon (Portugal) was used as inoculum. The reactor was fed with wastewater provided by a fish canning plant (A POVEIRA, S.A., Póvoa de Varzim, Portugal), collected after screening and coagulation/flotation processes performed at the plant for removal of solids and fat. The collected wastewater does not contain water streams resulting from the brining process as the fish canning plant separates the brine from the remaining wastewater, decreasing the amount of salt in the latter. Over almost 8 months, a total of 8 different batches of wastewater were collected at the fish canning plant, and each batch was used to feed the reactor during each operational phase (Table 1 ). In each batch, about $80 \mathrm{~L}$ of wastewater were collected and frozen stored in containers of $5 \mathrm{~L}$, which were further used to feed the reactor, one by one. This contributes to the representation of real scenarios where variations in the inflow wastewater are expected. The AGS-SBR operation was divided into eight phases, corresponding to the different batches of wastewater. The $\mathrm{pH}$ of the AGS process was monitored but not controlled.

\subsection{Analytical methods}

$\mathrm{COD}$ and $\mathrm{BOD}_{5}$ assays were performed in order to evaluate the $\mathrm{COD} /$ $\mathrm{BOD}_{5}$ ratio of the pre-treated wastewater, in accordance with standard methods (APHA, 1998). Sampling of the influent (wastewater), of the reactor bulk after anaerobic feeding and of the effluent discharged (outlet) was performed to assess the performance of the AGS-SBR in terms of carbon, nitrogen and phosphorous removal. Chloride concentration was also quantified and used as an indirect measurement of the $\mathrm{NaCl}$ present in the wastewater (Fig. S1). Prior to the physical-chemical analyses, samples were filtered using syringe nylon membrane filters ( $0.45 \mu \mathrm{m}$ pore-size) to remove suspended solids. Only the soluble COD was analyzed throughout reactor operation, in accordance with standard methods (APHA, 1998), and total organic carbon (TOC) was measured for selected wastewater samples using a Total Organic Carbon Analyzer (Shimadzu, Japan). Total nitrogen (TN), ammonia, nitrate, nitrite, phosphorus and chloride concentrations were determined with photometric test kits (Spectroquant ${ }^{\circledR}$, Merck Millipore, USA), according to the manufacturer's instructions. The $\mathrm{pH}$ of selected wastewater samples was checked; the $\mathrm{pH}$ at the effluent was measured throughout the operation (Fig. S2). Free ammonia concentration at the end of the aeration period was calculated according to Anthonisen et al. (1976), using the $\mathrm{pH}$ value and the $\mathrm{NH}_{4}^{+}-\mathrm{N}$ concentration at the effluent.

The total suspended solids (TSS) and volatile suspended solids (VSS) concentrations present in the effluent were determined in accordance with standard methods (APHA, 1998). 


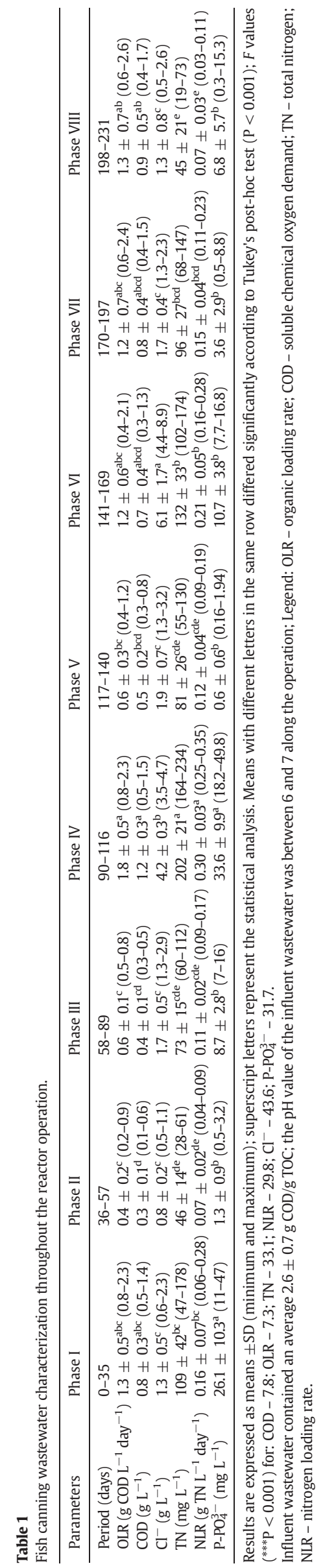

\subsection{Image analysis}

Duplicate AGS biomass samples were collected along reactor operation, more frequently during and after phase IV. Biomass samples were washed with phosphate-buffered saline (PBS) solution and incubated with PBS and formaldehyde (4\%) $(0.25: 1)$, for $2 \mathrm{~h}$ at $4{ }^{\circ} \mathrm{C}$. Biomass was washed with PBS and preserved in a mixture of PBS and ethanol (96\%) (1:1). Morphological and structural characteristics of granules were followed by quantitative image analysis (QIA), using a sample volume of $2 \mathrm{~mL}$ and with a total magnification of $15 \times$. QIA evaluated the equivalent diameter (Deq), number (\%), compactness, and robustness of the granules, according to Ramos et al. (2017). Equations used to determine robustness and compactness are presented as Supplementary material (Eqs. (S1) and (S2)).

\subsection{Bacterial community analysis}

\subsubsection{Genomic DNA extraction}

Mixed liquor AGS biomass samples were collected from the reactor during the aeration period, at the end of each operational phase. Granules were aseptically crushed using a pottering tube and a pestle. Genomic DNA extraction of the biomass suspension was performed using the UltraClean Microbial DNA Isolation Kit (Qiagen, Germany) according to manufacturer's instructions. DNA concentration was measured by fluorimetry using Qubit (Thermo Fisher Scientific, USA). The extracted DNA was stored at $-20^{\circ} \mathrm{C}$ for further use.

\subsubsection{Next-generation sequencing (NGS) and data analysis}

NGS was performed using DNA from AGS biomass. The microbial community analysis was performed based on sample singletons, without replicates. All procedures, from DNA amplification, libraries preparation, sequencing to bioinformatics data analysis were performed at GATC-Eurofins (Konstanz, Germany). Paired-end sequencing based on 16S rRNA phylogenetic gene was conducted (Illumina MiSeq platform) using two primers (357F - TACGGGAGGCAGCAG, Turner et al. (1999); 800R - CCAGGGTATCTAATCC, Kisand et al. (2002)) which cover V3-V4 hypervariable region. The microbiome analysis pipeline consisted of several steps: demultiplexing, primer clipping, merging, quality filtering and microbiome profiling. All reads with ambiguous bases were removed. Chimeric reads were identified and removed based on the denovo algorithm of UCHIME (Edgar et al., 2011) as implemented in the VSEARCH package (Rognes et al., 2016). The remaining set of highquality reads was processed using minimum entropy decomposition (MED) (Eren et al., 2013; Eren et al., 2015). To assign taxonomic information to each OTU, DC-MEGABLAST alignments of cluster representative sequences to the sequence database were performed. The lowest common taxonomic unit for each OTU was then selected from the set of best-matching reference sequences (reference sequences having a minimum of $70 \%$ identity with at least $80 \%$ of the representative sequence). Further processing of OTUs and taxonomic assignments were performed using the QIIME software package (version 1.9.1, http:// qiime.org/). Abundances of bacterial taxonomic units were normalized using lineage-specific copy numbers of the relevant marker genes to improve estimates (Angly et al., 2014). The core microbiome was assessed by identifying the bacterial genera (or family) quantified by Illumina sequencing in all biomass samples (for phase I, only sample from day 17 was considered). The raw sequence data obtained for the AGS biomass samples was deposited in Sequence Read Archive (SRA) from NCBI database, associated to the BioProject with accession number PRJNA645158.

\subsection{Statistical analysis}

Differences in COD, organic loading rate (OLR), TN, nitrogen loading rate (NLR), chloride and phosphate concentrations throughout the eight operational phases were statistically analyzed by one-way ANOVA. 
Significant differences between the means were determined by Tukey's post-hoc test in software R (https://www.R-project.org).

\section{Results}

\subsection{Reactor performance}

\subsubsection{Carbon, phosphorous and ammonium removal}

A $\mathrm{COD} / \mathrm{BOD}_{5}$ ratio between 2 and 2.5 was obtained for the pretreated wastewater, confirming its biodegradability. The fish canning wastewater was variable in composition and resulted in different carbon, nitrogen, phosphorous and chloride loadings applied to the AGSSBR (Table 1). Significant differences were found for each parameter between the eight operational phases (Table 1). COD, OLR, TN and NLR values were significantly higher during phase IV. Chloride concentration was significantly higher during phase VI, followed by phase IV, but no major differences were found in its concentration on the remaining phases. The highest phosphate concentrations were observed during phases I and IV, significantly different from those of the remaining phases.

The estimated concentration of salt in inflow wastewater was most of the time lower than $2.5 \mathrm{~g} \mathrm{NaCl} \mathrm{L}^{-1}$, with phases IV and VI presenting significantly higher estimated $\mathrm{NaCl}$ concentrations (6.9 and $10.1 \mathrm{~g} \mathrm{~L}^{-1}$, respectively) (Table 1). COD at the outlet varied during the AGS-SBR operation in response to the variable loadings (Table 1, Fig. 1a), but most of the times was below the discharge limit of $125 \mathrm{mg} \mathrm{O}_{2} \mathrm{~L}^{-1}$, with a COD removal between 70 and $85 \%$. Since the beginning of operation until phase III, with organic loadings up to $1.2 \mathrm{~kg} \mathrm{~m}^{-3}$ day ${ }^{-1}$, most of the COD was removed during the anaerobic feeding period. Mostly during phase IV, when the organic loading increased, but also in the succeeding phases, COD removal also occurred during the aeration period, mainly when COD in the wastewater was higher than $500 \mathrm{mg} \mathrm{L}^{-1}$.

The concentration of phosphorous in the effluent was lower than $2 \mathrm{mg} \mathrm{L}^{-1}$ during most of the time, in phases I, II, VII and VIII (Fig. 1b). Whenever phosphate release was higher at the end of the anaerobic feeding period (e.g. phases I, II and III), an improvement on phosphate removal during the aerobic period of the cycle was observed. Phosphate release was variable at the beginning of phase IV, decreasing from the end of phase IV until phase VII, when phosphate accumulation was again observed. A disturbance on phosphorous removal was observed during phase III, in which the phosphate concentration in wastewater increased. On phase IV, with the even higher increase of phosphate concentration in the wastewater, phosphorous removal was impacted to a higher extent. During phase $\mathrm{V}$, the influent wastewater contained less than $2 \mathrm{mg} \mathrm{P}-\mathrm{PO}_{3}^{-} \mathrm{L}^{-1}$, however, no removal was observed during phase VI, despite the increase of phosphorous concentration in the wastewater.

TN in the wastewater was the sum of organic and inorganic nitrogen (ammonium), in variable ratios. TN was measured in the influent, in reactor bulk liquid after anaerobic feeding, and in the effluent to verify if all organic nitrogen was hydrolyzed to ammonium during each treatment cycle. Overall, the TN values measured at the beginning and at the end of the aerobic period were similar (Fig. S3), indicating that most of the nitrogen compounds remained in the reactor bulk liquid. Most of the ammonium present in the AGS-SBR bulk liquid was converted to nitrate or to both nitrite and nitrate during the nitrification process (Fig. 1c, d, e). During the first 3 months of operation (phases I, II and III), ammonium was oxidized to nitrate without nitrite accumulation. Increasing the OLR up to $2.3 \mathrm{~kg} \mathrm{~m}^{-3}$ day $^{-1}$ on phase IV, ammonium conversion was temporarily inhibited. However, by the middle of this phase onwards, the nitrification recovered, mainly converting ammonium to nitrite and, to a lower extent, to nitrate. Ammonium oxidation was again interrupted for a short period at the beginning of phase VI, when both carbon and nitrogen load increased. Whenever nitrification started to be inhibited, the $\mathrm{pH}$ value and the ammonium content in the effluent were used to estimate the maximum free ammonium at the end of the aeration period. By the end of the treatment cycle, the estimated concentration of free ammonia in the

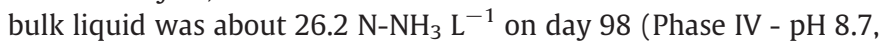
$160 \mathrm{mg} \mathrm{N}-\mathrm{NH}_{4}^{+} \mathrm{L}^{-1}$ ) and $13.8 \mathrm{~N}^{-N_{3} \mathrm{~L}^{-1}}$ on day 143 (Phase VI -

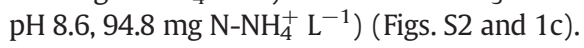

\subsection{Granular biomass dynamics}

The changes in biomass characteristics due to fluctuations in OLR were evaluated through image analysis and shown in Fig. 2. Representative images of the granules throughout the operational phases are presented in Fig. S4. The AGS inoculum was composed of $60 \%$ of large granules (average Deq above $1000 \mu \mathrm{m}$ ) and of $40 \%$ of intermediate granules (average Deq below $1000 \mu \mathrm{m}$ ) (Fig. 2a). This composition rapidly changed during reactor start-up, with intermediate granules constituting ca. $70 \%$ of the total biomass at the end of phase II. The highest percentage of intermediate granules was observed during phases IV and VIII ( 99.5 and $97.5 \%$, respectively). Such an increase could be related to the high strength of the inflow wastewater that caused breakage of the larger granules. In fact, the Deq of large granules decreased from $\pm 2400 \mu \mathrm{m}$ (phases I to III) to $1700 \mu \mathrm{m}$ (phase IV); an increase up to $2600 \mu \mathrm{m}$ was observed at the end of operation (Fig. 2b). The average Deq of intermediate granules was less variable along the operation (between 330 and $420 \mu \mathrm{m}$ ), increasing only during phase $\mathrm{V}$ (up to $800 \mu \mathrm{m}$ ). Despite the variability in granules size and Deq, the robustness and compactness of the granules did not present a significant variation over time, being comparable with the inoculum (between 0.7 and 0.8 ) (Fig. 2c, d).

The sludge bed volume and the concentration of solids in the effluent, used to assess the effects of the OLR variation on the reactor biomass content, are presented in Fig. 3. Bed volume was kept within an average value of $18.0 \pm 2.6 \mathrm{~cm}$, between phases I and middle of phase IV (Fig. 3a). During phase IV, a sudden increase was rapidly followed by a decrease in bed volume. Between the end of phase IV and middle of phase VIII, a regular increase was observed. Throughout the operation, the concentration of TSS in the outlet was higher than $50 \mathrm{mg} \mathrm{L}^{-1}$, indicating frequent biomass washout (Fig. $3 \mathrm{~b}$ ). The greatest variation in effluent TSS concentration was observed during phase I, with concentrations between 135 and $550 \mathrm{mg} \mathrm{TSS} \mathrm{L}^{-1}$. Biomass washout was stable during phase IV ( $\pm 270 \mathrm{mg} \mathrm{TSS} \mathrm{L}^{-1}$ ) and increased to its highest values during phase VII ( $\pm 340 \mathrm{mg} \mathrm{TSS} \mathrm{L}^{-1}$ ). The lowest TSS concentrations in the outlet were measured during phase $\mathrm{V}$, when the bed volume values were also lower.

\subsection{Microbial community analysis}

\subsubsection{Main bacterial phyla and classes}

Proteobacteria were overabundant in the inoculum (relative abundance of $64.8 \%$ ) followed by Bacteroidetes (17.5\%), both representing up to $82.5 \%$ of the total relative abundance. Acidobacteria (5.5\%) and Nitrospirae (1.7\%) were also identified in the inoculum. Proteobacteria and Bacteroidetes increased up to $95 \%$ of the total bacterial relative abundance in AGS biomass over operation, due to a decrease in diversity from phase IV onwards (Fig. 4a). Proteobacteria was dominant at almost all bioreactor phases except at the end of phases I and IV, where Bacteroidetes were more abundant. Acidobacteria lost relative abundance during and after phase IV and Nitrospirae were only detected until the end of phase III. The phylum Gemmatimonadetes was identified for the first time during phase III, presenting higher relative abundance during phase VIII (4.9\%). Regarding the most abundant classes within Proteobacteria and Bacteroidetes phyla (Fig. 4b, c), Gammaproteobacteria and Flavobacteriia were dominant during the initial phases of operation. From phase IV onwards, Gammaproteobacteria lost abundance to Betaproteobacteria, while Flavobacteriia lost their high relative abundance to Saprospiria and Cytophagia. Alphaproteobacteria and Chitinophagia were identified along the reactor operation. 


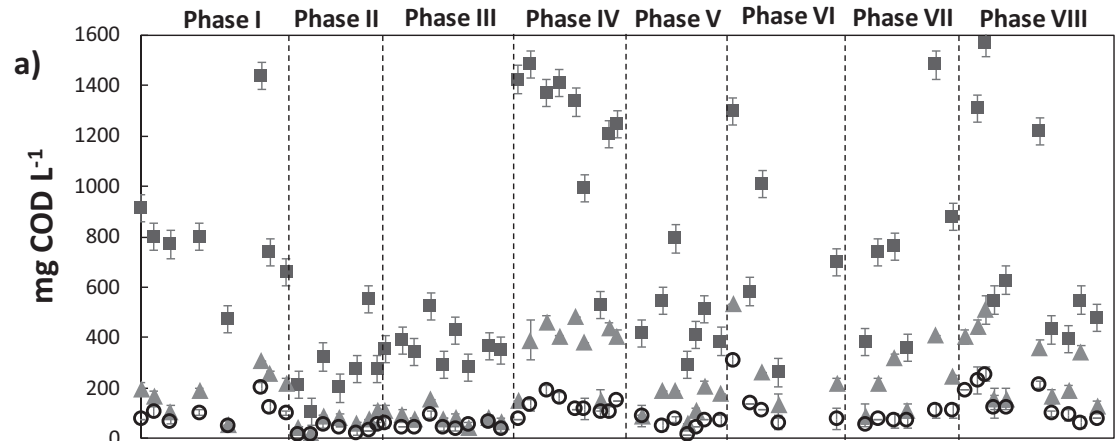

b)

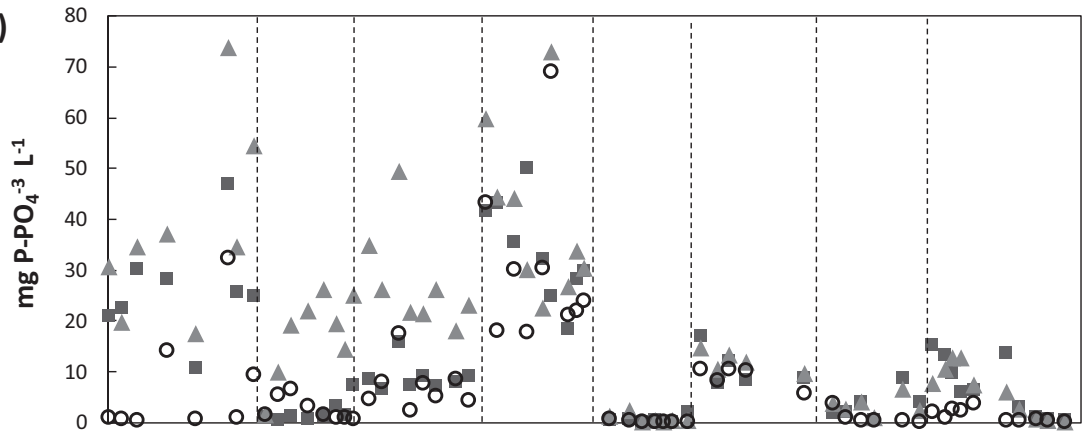

c)

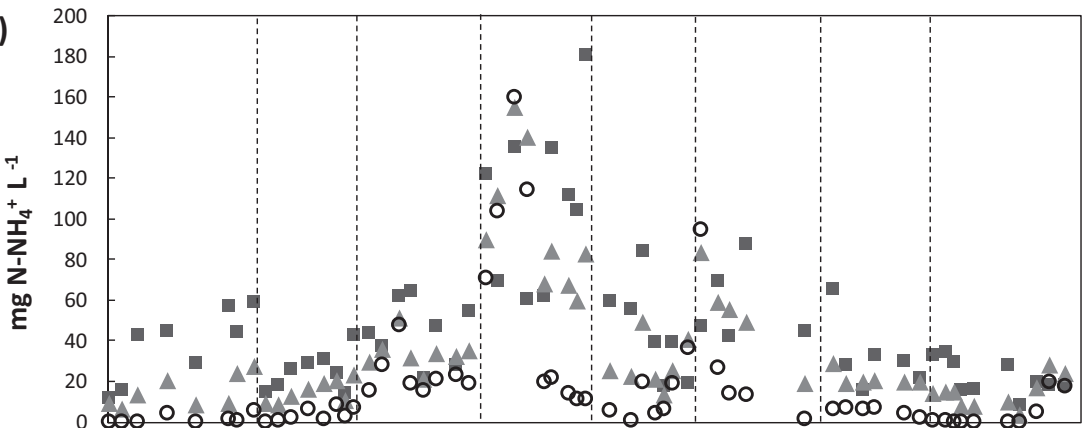

d)

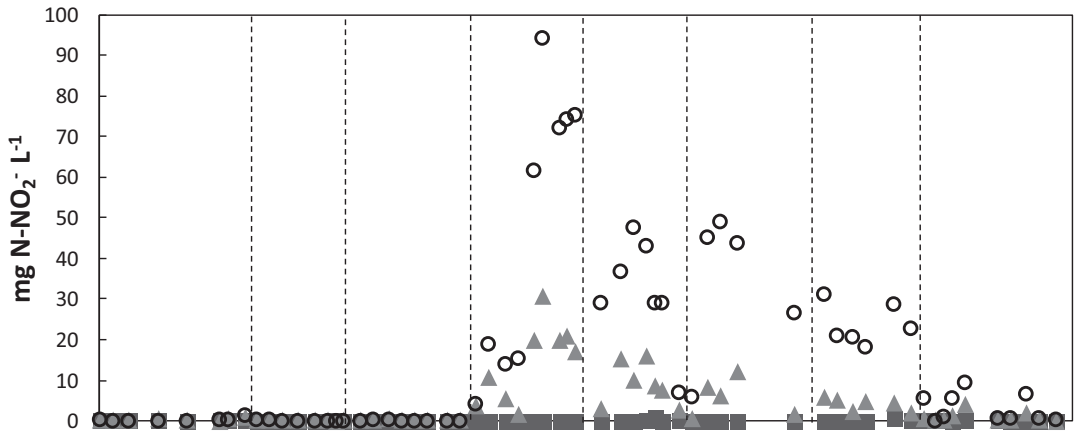

e)

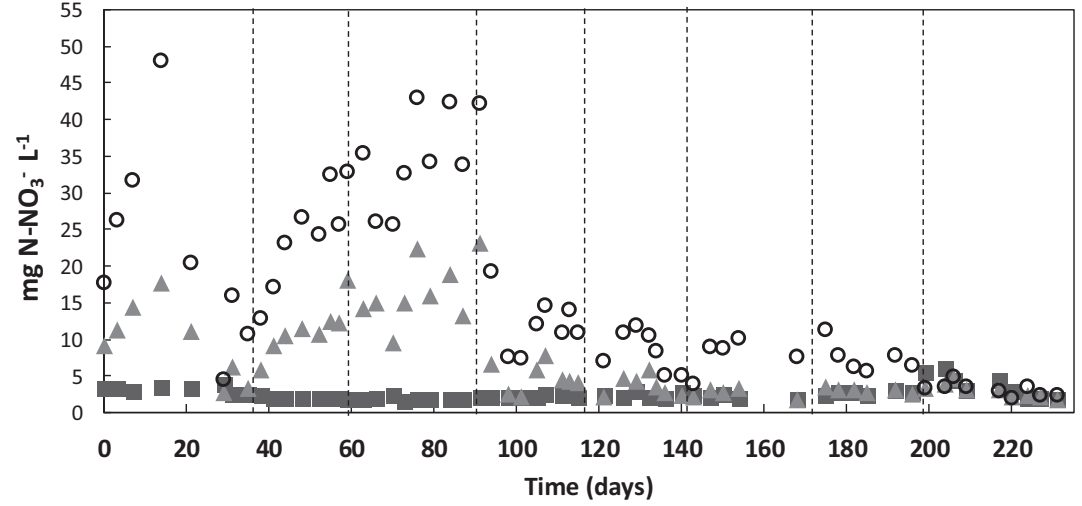

Fig. 1. $\mathrm{COD}$ (a), $\mathrm{P}-\mathrm{PO}_{4}^{3-}$ (b), $\mathrm{N}-\mathrm{NH}_{4}^{+}$(c), $\mathrm{N}-\mathrm{NO}_{2}^{-}$(d), and $\mathrm{N}-\mathrm{NO}_{3}^{-}$(e) concentrations along AGS-SBR operation. Concentration in the influent wastewater ( $\left.\mathbf{\square}\right)$, in the reactor bulk liquid after anaerobic feeding $(\boldsymbol{\Lambda})$ and effluent $(\mathrm{O})$ are shown. 
a)

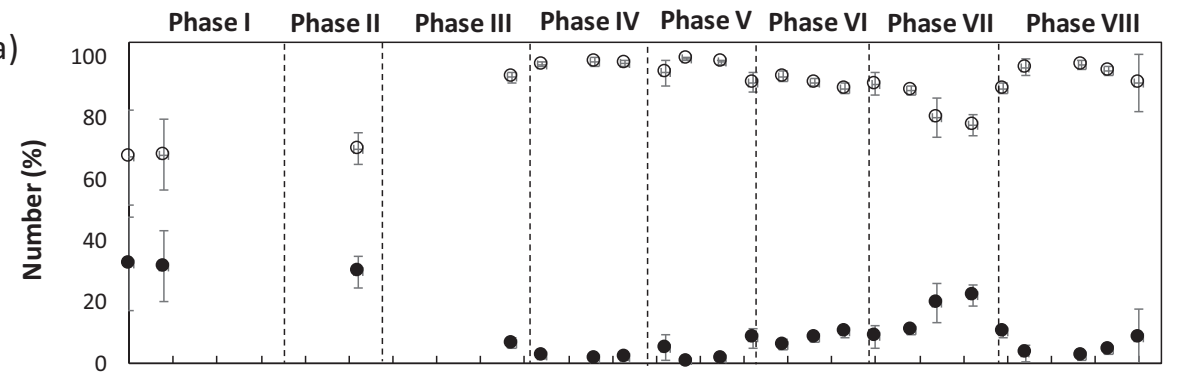

b)

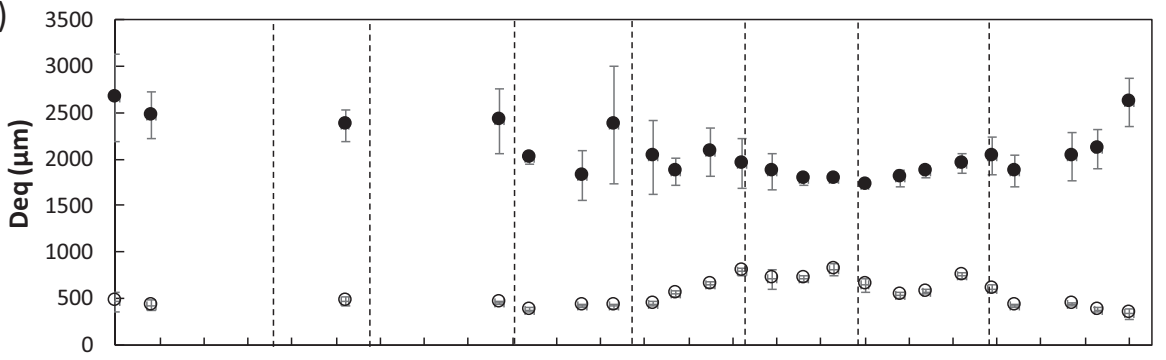

c)

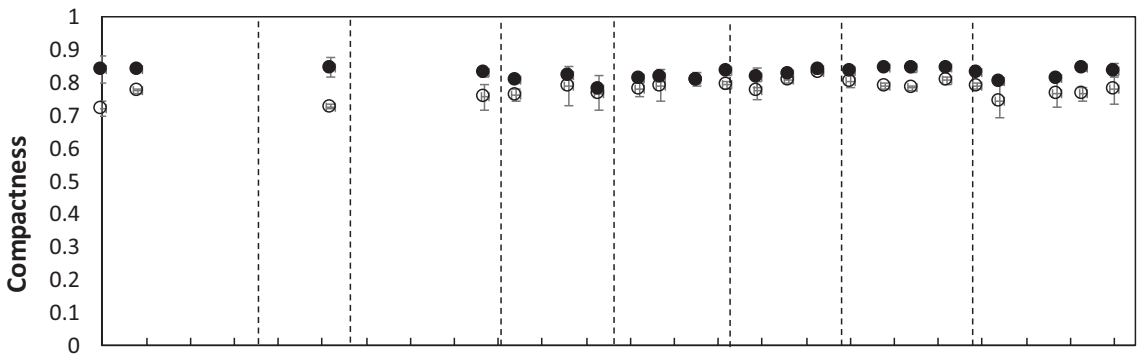

d)

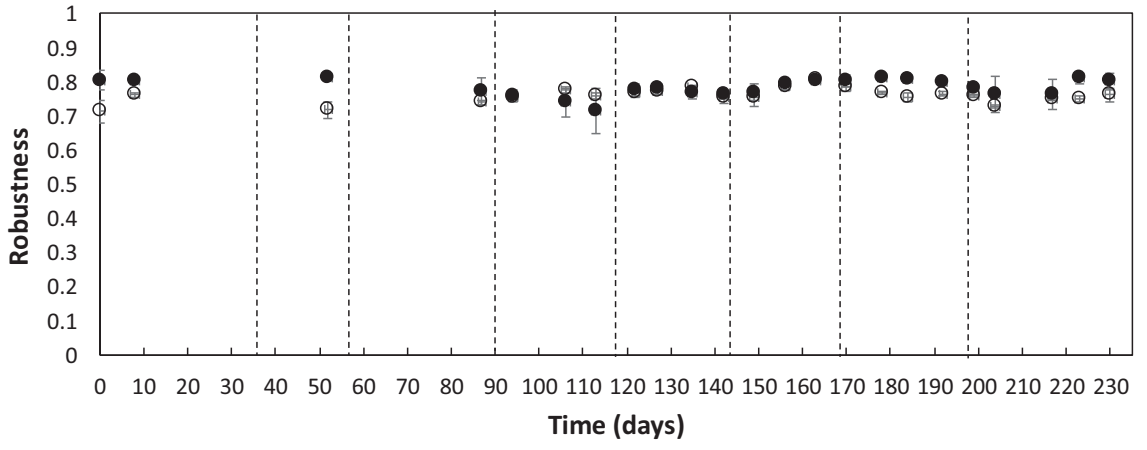

Fig. 2. Granules percentage (a); average Deq (b); compactness (c) and robustness (d) for large $(\bullet)$ and intermediate $(O)$ granules along the process.

\subsubsection{Most dominant bacterial families and genera}

Fig. 5 illustrates the main shifts in dominant bacterial families and genera between phases. Rhodobacteraceae, Flavobacteriaceae, Sphingomonadaceae, Methylococcaceae and Comamonadaceae were the five most abundant bacterial families present in the inoculum, representing ca. $41.4 \%$ of the total relative abundance. Excluding the Methylococcaceae, these families were present over time. Methylococcaceae was only detected until phase III, similarly to the Candidatus Competibacteraceae family, also present in the inoculum. The Caulobacteraceae family was identified with high relative abundance in all biomass samples, while Haliscomenobacteraceae, Cytophagaceae and Zoogloeaceae increased in relative abundance after phase IV.

Methylocaldum, Plasticicumulans, Novosphingobium, Phenylobacterium, Chryseobacterium bacterial genera and bacteria from the Rhodobacteraceae family were dominant in the inoculum accounting in total for ca. $34.8 \%$ of the total population. During phase IV, a major change of the bacterial community occurred, promoting the increase in Haliscomenobacter, Leadbetterella, Thauera, Taibaiella and Paracoccus abundancies that together accounted for ca. $37.4 \%$ of the total reads.
Pseudoxanthomonas and bacteria from the Comamonadaceae family reached their highest relative abundances between phases II and V. Micavibrio was only identified during phases V and VI, while Gemmatimonas, firstly identified in phase III, persisted and increased its relative abundance in the biomass at the end of operation.

\subsubsection{Nitrifiers and PAOs}

Nitrifying bacteria were identified in several biomass samples, sometimes within the most dominant bacterial genera (Fig. 5). Nitrosomonas, an AOB present in the inoculum, tended to disappear during phase I, but reappeared on phase VI achieving its highest relative abundance, indicating its resilience in the reactor biomass. Nitrospira, a NOB, was detected in the inoculum and prevailed in the biomass only until phase III with high relative abundance. Although at low relative abundance, bacteria associated to phosphorous removal were detected throughout the process. Candidatus Accumulibacter present in the inoculum $(2.42 \%)$, progressively decreased in abundance throughout phases I ( $0.71 \%)$ and II $(0.3 \%)$ while Tetrasphaera were detected between phases II and VIII (between 0.2 and 1\%) (data not shown). Gemmatimonas, also involved in phosphorous removal, were present 

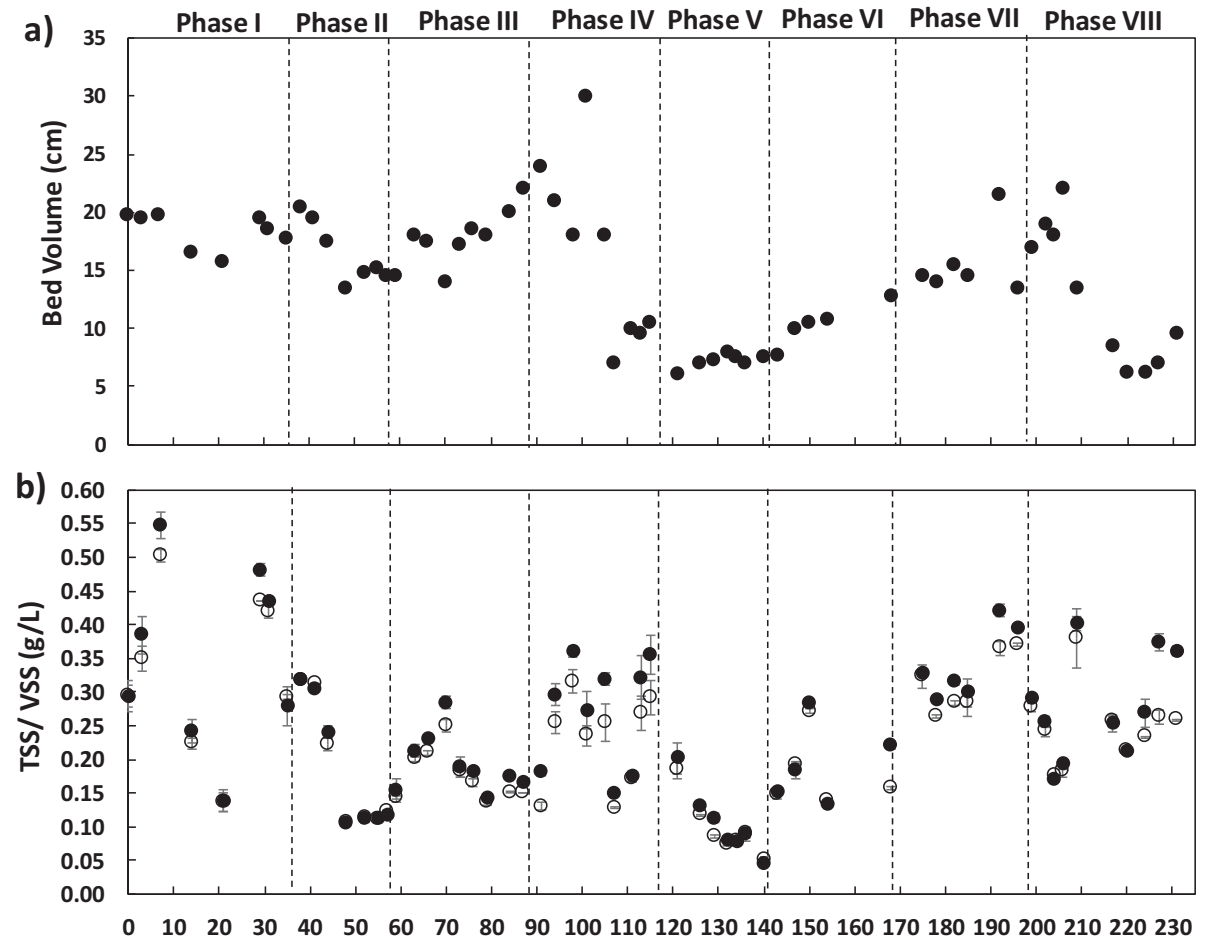

\section{Time (days)}

Fig. 3. AGS bed volume in bulk liquid $(\mathrm{a}, \bullet)$ and effluent TSS $(\bullet)$ and VSS $(\bigcirc)$ concentrations $(\mathrm{b})$ along reactor operation.

a)

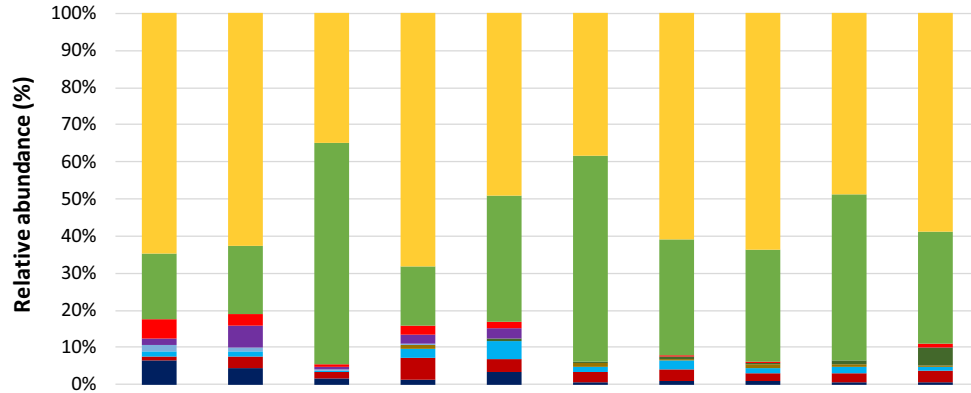

b)

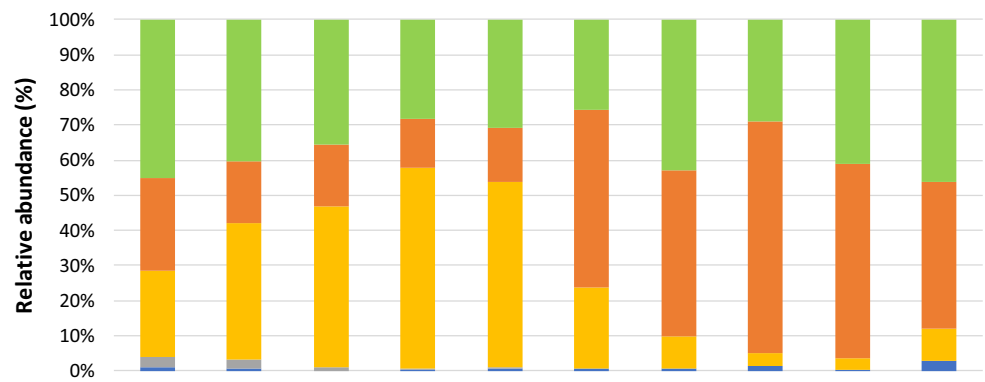

c)

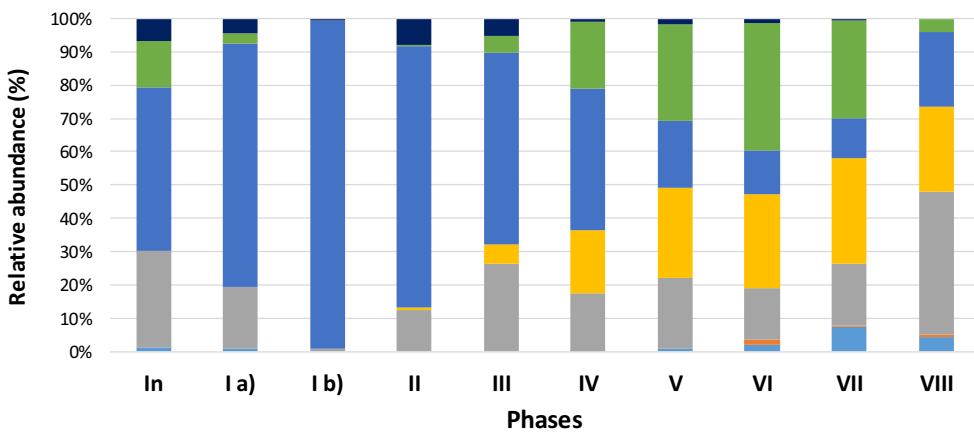

Proteobacteria

Bacteroidetes

- Acidobacteria

- Nitrospirae

Ignavibacteriae

- Gemmatimonadetes

Firmicutes

Cyanobacteria

- Actinobacteria

- Other

Alphaproteobacteria

Betaproteobacteria

Gammaproteobacteria

Deltaproteobacteria

Other

- Sphingobacteria

- Saprospiria

Flavobacteriia

Cytophagia

Chitinophagia

Bacteroidia

Other

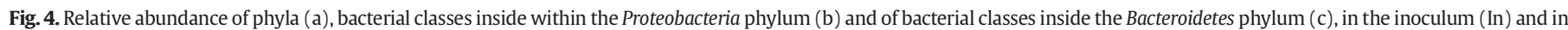
reactor biomass along operation; I a) and I b) represent samples collected during the middle and the end of phase I. 


\begin{tabular}{|c|c|c|c|c|c|c|c|c|c|c|}
\hline Family & In & Ia) & (b) & II & III & IV & V & VI & VII & VIII \\
\hline Rhodobacteraceae & 11.79 & 8.25 & 3.50 & 8.52 & 4.43 & 5.98 & 12.81 & 10.86 & 13.47 & 3.29 \\
\hline Flavobacteriaceae & 8.37 & 13.51 & 58.75 & 12.66 & 19.51 & 23.51 & 6.25 & 3.54 & 5.19 & 4.93 \\
\hline Sphingomonadaceae & 8.15 & 5.15 & 2.97 & 2.91 & 5.50 & 1.81 & 1.29 & 1.32 & 0.92 & 7.94 \\
\hline Methylococcaceae & 7.39 & 13.09 & 7.10 & 15.06 & 3.46 & 0.00 & 0.00 & 0.00 & 0.00 & 0.42 \\
\hline Comamonadaceae & 5.68 & 5.74 & 5.45 & 7.46 & 6.09 & 8.82 & 11.62 & 6.08 & 7.65 & 13.63 \\
\hline Candidatus Competibacteraceae & 5.54 & 9.46 & 5.77 & 14.05 & 10.17 & 0.22 & 0.00 & 0.00 & 0.00 & 0.00 \\
\hline Caulobacteraceae & 4.84 & 5.83 & 3.06 & 3.73 & 2.50 & 1.01 & 3.05 & 2.60 & 4.23 & 5.03 \\
\hline Xanthomonadaceae & 0.00 & 0.15 & 1.87 & 7.42 & 10.94 & 8.27 & 5.41 & 1.82 & 0.81 & 1.69 \\
\hline Chitinophagaceae & 5.08 & 3.43 & 0.52 & 2.00 & 9.02 & 9.56 & 6.64 & 4.64 & 8.25 & 12.96 \\
\hline Haliscomenobacteraceae & 2.10 & 0.57 & 0.00 & 0.11 & 1.53 & 11.14 & 8.80 & 9.91 & 10.39 & 0.58 \\
\hline Cytophagaceae & 0.00 & 0.00 & 0.00 & 0.13 & 1.58 & 10.64 & 8.22 & 7.84 & 14.02 & 6.26 \\
\hline Zoogloeaceae & 0.00 & 0.00 & 0.00 & 0.00 & 0.00 & 8.89 & 13.00 & 25.85 & 15.49 & 2.54 \\
\hline \multicolumn{11}{|l|}{ Best classification } \\
\hline Methylocaldum & 7.39 & 13.09 & 6.94 & 14.53 & 3.46 & 0.00 & 0.00 & 0.00 & 0.00 & 0.42 \\
\hline Rhodobacteraceae & 7.22 & 4.40 & 1.20 & 3.31 & 1.31 & 0.20 & 0.15 & 0.50 & 0.68 & 0.81 \\
\hline Plasticicumulans & 5.54 & 9.46 & 5.77 & 14.05 & 10.17 & 0.22 & 0.00 & 0.00 & 0.00 & 0.00 \\
\hline Novosphingobium & 5.15 & 2.99 & 0.85 & 0.55 & 0.54 & 0.00 & 0.24 & 0.17 & 0.00 & 0.29 \\
\hline Phenylobacterium & 4.84 & 5.83 & 3.06 & 3.73 & 2.50 & 1.01 & 3.05 & 2.60 & 4.23 & 5.03 \\
\hline Chryseobacterium & 4.70 & 9.25 & 57.61 & 11.62 & 15.24 & 19.33 & 3.63 & 1.16 & 3.40 & 2.57 \\
\hline Nitrospira & 1.53 & 5.70 & 0.82 & 2.48 & 2.77 & 0.00 & 0.00 & 0.00 & 0.00 & 0.00 \\
\hline Pseudoxanthomonas & 0.00 & 0.00 & 1.72 & 4.74 & 7.70 & 8.27 & 5.20 & 1.30 & 0.62 & 0.97 \\
\hline Comamonadaceae & 0.00 & 0.00 & 0.68 & 4.59 & 4.19 & 3.29 & 2.53 & 0.00 & 0.00 & 0.53 \\
\hline Ferruginibacter & 2.84 & 2.15 & 0.39 & 1.22 & 4.90 & 2.04 & 2.26 & 1.03 & 1.65 & 3.09 \\
\hline Flavobacterium & 3.67 & 1.77 & 0.36 & 0.82 & 3.72 & 1.98 & 1.24 & 0.79 & 0.13 & 0.55 \\
\hline Haliscomenobacter & 1.87 & 0.57 & 0.00 & 0.11 & 1.53 & 11.14 & 8.56 & 9.84 & 10.39 & 0.58 \\
\hline Leadbetterella & 0.00 & 0.00 & 0.00 & 0.00 & 0.19 & 8.75 & 5.00 & 2.37 & 6.12 & 4.87 \\
\hline Thauera & 0.00 & 0.00 & 0.00 & 0.00 & 0.00 & 8.55 & 12.43 & 25.60 & 15.49 & 2.54 \\
\hline Taibaiella & 0.00 & 0.00 & 0.00 & 0.00 & 0.12 & 4.71 & 1.12 & 0.58 & 0.00 & 6.04 \\
\hline Paracoccus & 0.69 & 0.54 & 0.46 & 1.91 & 1.66 & 4.25 & 9.29 & 8.30 & 11.07 & 1.21 \\
\hline Micavibrio & 0.00 & 0.00 & 0.00 & 0.00 & 0.00 & 0.00 & 7.12 & 1.99 & 0.00 & 0.00 \\
\hline Nitrosomonas & 1.60 & 1.13 & 0.00 & 0.30 & 0.00 & 0.00 & 0.00 & 5.42 & 0.81 & 0.00 \\
\hline Ohtaekwangia & 0.00 & 0.00 & 0.00 & 0.13 & 0.52 & 1.26 & 2.03 & 4.69 & 6.18 & 0.90 \\
\hline Sphingomonadaceae & 1.59 & 1.40 & 1.22 & 1.26 & 1.90 & 0.88 & 0.62 & 1.15 & 0.74 & 5.04 \\
\hline Gemmatimonas & 0.00 & 0.00 & 0.00 & 0.00 & 0.33 & 0.46 & 0.73 & 0.38 & 1.28 & 4.89 \\
\hline
\end{tabular}

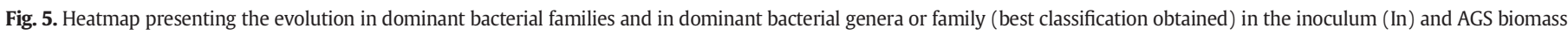
along the reactor operational phases; only the first five dominant bacterial families/genera from each biomass sample were considered.

in the process from phase III on, reaching the highest abundance during phase VIII (4.9\%) (Fig. 5). Therefore, a succession of genera related to phosphorous removal was observed with Accumulibacter, Tetrasphaera and Gemmatimonas detected at higher abundance at the beginning, middle and end of reactor operation, respectively.

\subsubsection{Core microbiome}

A detailed analysis revealed that some microorganisms were present in all biomass samples over the whole period. The bacterial groups present in the AGS microbiome belonged to the Bacteroidetes (Ferruginibacter, Terrimonas, Chryseobacterium, Flavobacterium, Haliscomenobacter), Proteobacteria (Phenylobacterium, Hyphomicrobium, Rhodobacteraceae, Paracoccus, Rhodobacter, Sphingomonadaceae, Acidovorax, Ottowia), and Cyanobacteria (Microcystis and Prochlorococcus) phyla. Most of these bacteria presented a high relative abundance, constituting ca. 31 to $48 \%$ of the relative abundance of all AGS biomass samples. The highest abundance of shared bacterial phylotypes was obtained at the end of phase IV (ca. 48\%), characterized by an increase in Chrysobacterium, Haliscomenobacter and Paracoccus, which in total comprised almost 35\% of the total abundance (Fig. 5).

\subsubsection{Bacteria associated to carbon degradation and accumulation}

Several bacteria involved in different processes of carbon removal were identified in AGS microbiome. Bacterial genera with proteolytic activity namely Chryseobacterium and Haliscomenobacter were present in biomass over operation. In addition, members of the Chitinophagaceae family that present hydrolytic activity, such as Ferruginibacter, were detected throughout operation, while Taibaiella was enriched during phase IV. Members of the Cytophagaceae family (e.g. Leadbetterella and Ohtaekwangia) can hydrolyze proteins and polysaccharides. Flavobacterium, Thauera, Paracoccus, Chryseobacterium, Phenylobacterium and members from the Rhodobacteraceae, Xanthomonadaceae and Sphingomonadaceae families, with high relative abundance in the granular biomass, are associated to EPS production. Among PHA accumulating microorganisms, two bacterial genera were identified: Plasticicumulans, abundant in the inoculum, and Thauera, enriched during phase IV.

\section{Discussion}

The AGS process was able to treat fish canning wastewater and was robust to overcome the challenge of treating variable organic loadings between 0.2 and $2.3 \mathrm{~kg} \mathrm{~m}^{-3} \mathrm{day}^{-1}$ without the need for biomass acclimation. Stable nitrification was achieved, only temporarily inhibited by higher organic load periods that affected NOB activity, whereas a succession of different PAO populations assured phosphorous removal to levels complying with discharge limits. The bacterial groups present in the core microbiome were mainly associated to EPS production, contributing for the resilience of the system.

The characteristics of the wastewater applied during the initial phases of reactor operation were favourable to all removal processes: COD, phosphorous and ammonium concentrations in the outlet complied most of times with the discharge limits. The increase in nitrogen and phosphorous content in the wastewater during phase III affected phosphorous and ammonium removal. However, a more pronounced negative effect on the removal processes was observed during phase IV, characterized by significantly higher organic and nitrogen loading rates (OLR, NLR). During this phase, not all carbon uptake was performed during the anaerobic period. This led to the presence of excess carbon during the aerated period, which allowed for the overgrowth of suspended heterotrophic bacteria. Similar events were observed when extra COD was available favouring the growth of fast-growing heterotrophic microorganisms, charaterized initially as a suspended biomass layer on top of the aerobic granules bed volume (e.g. phase 
VIII). The suspended biomass was possibly dominated by filamentous bacteria, which can grow at the expense of complex substrates while outcompeting for oxygen, required for nitrification and phosphorous removal processes (de Kreuk et al., 2005; de Kreuk et al., 2010). Indeed, from phase IV onwards, the presence of a high relative abundance in the AGS of Haliscomenobacter, a known aerobic heterotrophic filamentous bacteria, naturally occurring in activated sludge (Kämpfer et al., 1995), corroborates this hypothesis. Other studies have shown that filamentous bacteria can proliferate in the presence of extra COD and trigger the destabilization of the granular biomass (Moura et al., 2018; Winkler et al., 2018). In fact, the bacterial overgrowth observed during periods of higher organic load (phases IV and VIII) was also associated to the main changes in biomass characteristics, presenting the highest percentage of intermediate granules in the biomass. Slow-growing bacteria, such as nitrifiers and PAOs, are important species for establishing stable granules (Pishgar et al., 2019). The competition for oxygen and nutrients between filamentous and slow-growing bacteria can, therefore, promote a change in the microbial composition within the granules. In bigger granules, this effect can be more pronounced as the inner layers of the granule receive a limited amount of oxygen and nutrients, and as such the activity and composition of slow-growing bacteria is reduced and the disintegration process is expected to be faster. Therefore, the increased suspended biomass could have promoted the disintegration of large granules and worse settling properties, which resulted in biomass washout and sludge bed volume reduction. Despite this, the process was able to rapidly form larger, and, possibly, denser granules, which associated with the recovery of the settling properties, allowed a bed volume increase during the periods with lower organic load (between phases IV and VIII). This indicates that fish canning wastewater allows the establishment of dense and stable granules, as also observed by Carrera et al. (2019). Despite these variations, the granular biomass did not lose the initial morphological characteristics, as indicated by compactness and robustness values obtained along the study.

Suspended biomass overgrowth did not keep COD in the treated effluent below the discharge limits. Fish canning wastewater is composed by complex organic molecules, possibly slowly biodegradable, which need initial extracellular hydrolysis and longer biodegradation periods. Therefore, an increase in OLR might not only limit the carbon uptake by PAOs and other polyhydroxyalkanoates (PHA) accumulating bacteria during anaerobic feeding, but also the heterotrophic degradation during the aerobic period (Corsino et al., 2016; de Kreuk et al., 2010).

The high content of solids in the effluent observed throughout the operation (above $50 \mathrm{mg} \mathrm{TSS} \mathrm{L}^{-1}$ ) is possibly expected during fish wastewater treatment. AGS processes treating industrial wastewater with variable composition can result in solids washout, demanding for a subsequent solids separation system (Carrera et al., 2019).

Regarding nutrients removal, the higher nitrogen load present during phase IV resulted in additional stress to ammonium and phosphorous removal processes. The interruption of nitrification was possibly due to a cascade of processes initiated by the higher OLR entering the reactor that allowed for the heterotrophic growth of suspended biomass and consequently reduced the amount of oxygen available for ammonium oxidation. This event led to the increase in both alkalinity and ammonium concentration in the reactor bulk liquid, resulting in the accumulation of high concentrations of free ammonia (up to 26.2 and $13.8 \mathrm{mg} \mathrm{N}-\mathrm{NH}_{3} \mathrm{~L}^{-1}$, at the beginning of phases IV and VI, respectively). Free ammonia is a known inhibitor of the nitrification activity in WWTPs (Liu et al., 2019; Tang and Chen, 2015). Among nitrifiers, AOB are known to be more resistant to free ammonia than NOB (Anthonisen et al., 1976; Liu et al., 2019). In a previous study, NOB were found to be more sensitive than AOB to a concentration of $16.8 \mathrm{mg} \mathrm{N}-\mathrm{NH}_{3} \mathrm{~L}^{-1}$, resulting in the accumulation of nitrite after the treatment with free ammonia (Qian et al., 2017). Nitrosomonas (AOB) were identified in the AGS at the beginning and at the end of reactor operation, indicating its prevalence in the process, while Nitrospira (NOB) were only detected with high relative abundance until the end of phase III. This is in agreement with the results from reactor performance, which showed a fast recovery of ammonium but not of nitrite oxidation, corroborating that NOB were the most affected nitrifiers. The disturbances occurred during phase IV might have decreased NOB activity but also their numbers, possibly through biomass washout, reducing the possibility of a fast process recovery. Besides free ammonia, several studies reported that NOB were more sensitive than $\mathrm{AOB}$ to other operational factors (e.g., carbon to nitrogen ratio, oxygen dissolved, pH) (Liu et al., 2019; Rollemberg et al., 2018). Phosphorous removal can also be an unstable process when nitrification is disturbed, since the activity of PAO can be compromised by both free ammonia and nitrite accumulation (Liu et al., 2019; Saito et al., 2004). Free ammonia (17.76 $\mathrm{mg} \mathrm{N}-\mathrm{NH}_{3} \mathrm{~L}^{-1}$ ) was found to inhibit phosphorous removal in a granule-based system (Zheng et al., 2013). However, in other studies the inhibitory effect of nitrite on phosphate removal was reported to be even more significant, with concentrations of 6 and $8 \mathrm{mg} \mathrm{N}$ $\mathrm{NO}_{2}^{-} \mathrm{L}^{-1}$ completely inhibiting phosphate removal (Meinhold et al., 1999; Saito et al., 2004). In addition, Bassin et al. (2011) observed a reduced phosphate removal of an AGS process in the presence of a nitrite concentration above $4 \mathrm{mg} \mathrm{N}-\mathrm{NO}_{2}^{-} \mathrm{L}^{-1}$. In the current study, the accumulation of a high concentration of nitrite in bulk liquid during phases IV, $\mathrm{V}$ and VI, together with extremely low phosphorous content present in the inflow wastewater during phase $V$, may have caused a negative impact on PAOs activity and numbers, since phosphate release and consequent removal ability was reduced during phases IV and VI. Different bacteria associated to phosphorous removal such as Candidatus Accumulibacter, the most widely known PAO (Marques et al., 2017), Tetrasphaera, a putative PAO present in high abundance in full-scale plants performing phosphorous removal (Marques et al., 2017) and Gemmatimonas, also a PAO identified in AGS processes, and the only bacterial genera representative of the phylum Gemmatimonadetes (Li et al., 2020; Zhang, 2003) were successively identified with higher relative abundance in a chronological sequence throughout reactor operation. The fact that Candidatus Accumulibacter takes up VFAs while Tetrasphaera can degrade other complex substrates (Marques et al., 2017; Weissbrodt et al., 2014) might explain the detection of Accumulibacter at earlier phases while Tetrasphaera was only detected later in the process. Phosphorous removal was again observed by the end of reactor operation, when nitrite concentration decreased, indicating a recovery of this process. Gemmatimonas bacteria possibly contributed to phosphorous removal during phase VIII. Besides the effect of nitrite accumulation on PAOs activity, the operational periods with lower concentration of phosphorous in the wastewater were probably detrimental to PAOs, which could be outcompeted for VFAs and by other PHA accumulating microorganisms, such as glycogen-accumulating organisms (GAOs), known competitors of PAOs in the absence of phosphorous (Weissbrodt et al., 2014). Although GAOs were not identified in the AGS microbiome, other PHA accumulating bacteria, such as Thauera (Oshiki et al., 2008) were present with higher relative abundance at the end of phase IV. These bacteria could have outcompeted PAOs for carbon uptake during the periods of lower phosphorous concentration in the influent wastewater, possibly due to the numerical advantage previously gained over PAOs.

The presence of high salt concentrations in the fish canning wastewater can also be a source of stress to the biological removal processes (Corsino et al., 2016). In the present study, the estimated NaCl concentration did not rise above $10.1 \mathrm{~g} \mathrm{~L}^{-1}$. The sole effect of salt on carbon, nitrogen and phosphorous removal in AGS processes treating high salinity wastewater has been previously investigated by other researchers, which have shown that COD removal was not affected by salt concentrations between 20 and $75 \mathrm{~g} \mathrm{NaCl} \mathrm{L}^{-1}$ (Corsino et al., 2016; Pronk et al., 2014). Other studies have also shown that AOB were not affected by salt concentrations up to $50 \mathrm{~g} \mathrm{NaCl} \mathrm{L}^{-1}$, while NOB activity was slightly reduced at $11 \mathrm{~g} \mathrm{NaCl} \mathrm{L}^{-1}$ and was completely inhibited at concentrations above $20 \mathrm{~g} \mathrm{NaCl} \mathrm{L}^{-1}$ (Bassin et al., 2011; Corsino et al., 2016; Pronk et al., 2014). Phosphorous removal was found to be affected by a salt concentration above $21 \mathrm{~g} \mathrm{NaCl} \mathrm{L}^{-1}$ (Pronk et al., 2014). Several 
researchers observed a cascade inhibition effect in AGS processes: salt affected first nitrite oxidation which accumulation had in turn a detrimental effect on phosphate removal (Bassin et al., 2011; Pronk et al., 2014). Considering those previous studies, salt would be expected to have a greater effect on NOB activity, mostly above $10 \mathrm{~g} \mathrm{NaCl} \mathrm{L}^{-1}$, compared to AOB or PAO activity. The first increase of salt up to ca. $6.9 \mathrm{NaCl}$ $\mathrm{L}^{-1}$ occurred concomitantly with the increase of carbon and nitrogen load (phase IV). Results indicate that the organic and nutrients load increase can explain most of the changes occurred on carbon and nutrients removal independently of salt increase. Taking into consideration the expected high sensibility of NOB, the increased average salt concentration applied during phase $\mathrm{VI}$ (ca. $10.1 \mathrm{~g} \mathrm{NaCl} \mathrm{L}^{-1}$ ) did not seem to additionally affect nitrite oxidation to nitrate, when both carbon and nitrogen loads were lower. Nevertheless, the combined effect of the increase in free ammonia and salt concentration on NOB activity during phase IV cannot be excluded.

Although not acclimated, the aerobic granules were able to treat the fish canning wastewater and despite the disturbances caused by the variability in wastewater composition, the AGS process did not lose the ability to remove phosphorous or to perform nitrification. The difficulty in obtaining a higher number of reads of PAO and AOB is probably associated to the lower numbers present in the biomass when compared to the dominant and diverse fast-growing heterotrophic bacteria, enriched by the availability of organic matter.

Bacteria with hydrolytic and carbon degradation activity comprised one of the most abundant groups identified throughout the study. These bacteria were possibly required for the conversion of complex to simpler substrates (Weissbrodt et al., 2014). Chryseobacterium are chemoorganotrophic bacteria with strong proteolytic activity, which also may present filamentous cells (Hugo et al., 2020). These bacteria appeared to be outcompeted by other carbon degraders after phase IV. Possible competitors of Chryseobacterium were the filamentous bacteria Haliscomenobacter, known to have proteolytic activity (Parte et al., 2010), but also Ferruginibacter and Taibaiella, known aerobic heterotrophs found in AGS processes with hydrolytic activity (McBride et al., 2014; Szabó et al., 2017; Zhang et al., 2019). The ability to degrade complex substrates might have also led to the enrichment of members of the Cytophagaceae family during phase IV, associated to the hydrolysis of proteins and polysaccharides in biological processes (McBride et al., 2014). Leadbetterella and Ohtaekwangia (Cytophagaceae family members) were identified in this study, being also present in other AGS processes (Świątczak and Cydzik-Kwiatkowska, 2018; Xia et al., 2018).

Several bacterial families and genera have been assigned to EPS production. Flavobacterium, Thauera and Paracoccus were identified as polysaccharide producers able to promote the production of key chemical factors for granule maturation and long-term integrity (Pishgar et al., 2019; Szabó et al., 2017). The genus Chryseobacterium has a high autoaggregation index, indicating the ability to aggregate and secrete proteins to strengthen bacterial clusters (Adav et al., 2010) and Phenylobacterium was identified during the granulation process in a bioreactor (Zhou et al., 2014). Members of the Rhodobacteraceae family were identified as biofilm producers, with a role in granulation (Pishgar et al., 2019) and Xanthomonadaceae and Sphingomonadaceae bacterial families were reported to include EPS producing bacteria (Szabó et al., 2017). Until the disturbance caused by the organic load, granules structure was possibly maintained by the presence of Chryseobacterium, Rhodobacteraceae and Sphingomonadaceae (e.g. Novosphingobium). After this disturbance, other putative EPS bacterial groups, such as Thauera, Paracoccus and Xanthomonadaceae (e.g., Pseudoxanthomonas) might have become the main contributors for granules stability. EPS production plays an important role in the formation and maintenance of granules stability and integrity, protecting bacteria from severe external conditions (Szabó et al., 2017; Xia et al., 2018). The enrichment of different EPS producing bacteria along the wastewater treatment observed in this study may be related to that. Indeed, regarding the persistency of different bacterial families and genera until the end of the operation (core microbiome), many share the role of putative EPS producers (Chryseobacterium, Flavobacterium, Paracoccus, Phenylobacterium, Rhodobacteriaceae and Sphingomonadaceae members). This supports the importance of EPS producers in the long-term stability of the AGS treatment process treating industrial wastewater.

During the higher organic loading period (phase IV), substantial shifts occurred between dominant hydrolytic bacteria and EPS producers, but possibly also between PHA accumulating microorganisms. In this study, Plasticicumulans, a PHA accumulating bacterium from the Candidatus Competibacteraceae family (Jiang et al., 2011) might have been outcompeted by Thauera, which can also accumulate PHAs (Oshiki et al., 2008).

The overlap of metabolic functions among different bacterial groups allowed the competition and establishment of microbial communities better adapted to the wastewater quality, contributing in this way to the flexibility and increased AGS process stability. This redundancy allowed that negatively impacted bacteria could be replaced by others to fill their ecological niche in the microbiome thus avoiding process failure.

The possibility of using non-adapted granular biomass is advantageous not only for the rapid start-up of reactors but also for posterior additions in case of biomass loss to allow fast recovery of AGS processes. In addition, with the continuous spreading of AGS processes in urban WWTPs, the access to mature granules for reactors inoculation would be facilitated and perhaps the AGS biomass surplus can also be used. Although AGS proved to be able to deal with higher organic loads for long time periods, the AGS process stability, mainly of NOB and PAO activities, was temporally disturbed. At a larger scale, where equalization tanks generally exist for collecting and mixing streams, the concentration of pollutants during such periods could be in part attenuated. Nevertheless, the AGS system was robust and efficient for treating alternate wastewater composition, a scenario that characterizes industrial streams.

\section{Conclusion}

Biomass acclimation and granulation was not a pre-requisite for the start-up and long-term efficient treatment of variable fish canning wastewater composition using an AGS process. Overall, the nonadapted AGS presented good performance for all removal processes, being temporarily disturbed by a period of higher OLR. Carbon removal was mostly affected by higher OLR (above $2 \mathrm{~kg} \mathrm{~m}^{-3}$ day $^{-1}$ ), while higher carbon and nitrogen loads promoted a sequential effect on nutrients removal processes. A flow of inhibition steps is proposed: heterotrophic overgrowth resulting in nitrification inhibition, free ammonia accumulation, ammonium oxidation recovery, nitrite build-up and lower phosphorous removal. The AGS bacterial community was dynamic along reactor operation, with a major microbiome change occurring during the higher OLR period. NOB and PAO were the most affected bacterial groups, corroborating performance results. In the core microbiome, a great diversity of dominant heterotrophic bacteria associated to substrate degradation and EPS production was present, contributing with their resilience and adaptation capacities to the long-term stability of the AGS biomass. Salt variation was not detrimental to any of the biological processes, possibly due to the presence of EPS-producing bacteria. This study shows that microbial diversity and metabolic overlapping are at the basis of the stability of AGS processes, which, without need for acclimation, can be used to treat food industry wastewater with variable composition.

\section{CRediT authorship contribution statement}

Ana M.S. Paulo: Investigation, Formal analysis, Writing - original draft. Catarina L. Amorim: Conceptualization, Writing - review \& editing. Joana Costa: Software, Formal analysis. Daniela P. Mesquita: Software, Writing - review \& editing. Eugénio C. Ferreira: Supervision, 
Writing - review \& editing. Paula M.L. Castro: Conceptualization, Supervision, Writing - review \& editing, Funding acquisition.

\section{Declaration of competing interest}

The authors declare that they have no known competing financial interests or personal relationships that could have appeared to influence the work reported in this paper.

\section{Acknowledgments}

This work was supported by National Funds from FCT - Fundação para a Ciência e a Tecnologia, through the project MULTIBIOREFINERY - SAICTPAC/0040/2015 (POCI-01-0145-FEDER-016403). We would also like to thank the scientific collaboration of CBQF under the FCT project UID/Multi/50016/2019 and of CEB under the FCT project UID/BIO/ 04469/2019 and BioTecNorte operation (NORTE-01-0145-FEDER000004) funded by the European Regional Development Fund under the scope of Norte2020 - Programa Operacional Regional do Norte. We would like to thank "A Poveira S.A." (Póvoa de Varzim, Portugal) for providing the fish canning wastewater.

\section{Appendix A. Supplementary data}

Supplementary data to this article can be found online at https://doi. org/10.1016/j.scitotenv.2020.144007.

\section{References}

Adav, S.S., Lee, D.-J., Lai, J.-Y., 2010. Potential cause of aerobic granular sludge breakdown at high organic loading rates. Appl. Microbiol. Biotechnol. 85, 1601-1610. https://doi. org/10.1007/s00253-009-2317-9.

Amorim, C.L., Moreira, I.S., Duque, A.F., Van Loosdrecht, M.C.M., Castro, P.M.L., 2017. Aerobic granular sludge: treatment of wastewaters containing toxic compounds. In: Val del Río, A. Campos Gómez, J.L., Mosquera-Corral A. (Eds.), Technologies for the Treatment and Recovery of Nutrients From Industrial Wastewater. IGI Global, pp. 231-263.

Angly, F.E., Dennis, P.G., Skarshewski, A., Vanwonterghem, I., Hugenholtz, P., Tyson, G.W., 2014. CopyRighter: a rapid tool for improving the accuracy of microbial community profiles through lineage-specific gene copy number correction. Microbiome 2. https://doi.org/10.1186/2049-2618-2-11.

Anthonisen, A.C., Loehr, R.C., Prakasam, T.B.S., Srinath, E.G., 1976. Inhibition of nitrification by ammonia and nitrous-acid. J. Water Pollut. Control Fed. 48, 835-852.

APHA, 1998 1998. In. American Public Health Association, Washington DC.

Bassin, J.P., Pronk, M., Muyzer, G., Kleerebezem, R., Dezotti, M., van Loosdrecht, M.C.M., 2011. Effect of elevated salt concentrations on the aerobic granular sludge process: linking microbial activity with microbial community structure. Appl. Environ. Microbiol. 77, 7942-7953. https://doi.org/10.1128/aem.05016-11.

Carmen, F., Anuska, M.C., Luis, C.J., Ramon, M., 2013. Post-treatment of fish canning effluents by sequential nitrification and autotrophic denitrification processes. Process Biochem. 48, 1368-1374. https://doi.org/10.1016/j.procbio.2013.06.005.

Carrera, P., Campo, R., Mendez, R., Di Bella, G., Campos, J.L., Mosquera-Corral, A., et al., 2019. Does the feeding strategy enhance the aerobic granular sludge stability treating saline effluents? Chemosphere 226, 865-873. https://doi.org/10.1128/aem.050161110.1016/j.chemosphere.2019.03.127.

Chowdhury, P., Viraraghavan, T., Srinivasan, A., 2010. Biological treatment processes for fish processing wastewater - a review. Bioresour. Technol. 101, 439-449. https:// doi.org/10.1016/j.biortech.2009.08.065.

Corsino, S.F., Capodici, M., Morici, C., Torregrossa, M., Viviani, G., 2016. Simultaneous nitritation-denitritation for the treatment of high-strength nitrogen in hypersaline wastewater by aerobic granular sludge. Water Res. 88, 329-336. https://doi.org/ 10.1016/j.watres.2015.10.041.

Corsino, S.F., Capodici, M., Torregrossa, M., Viviani, G., 2017. Physical properties and extracellular polymeric substances pattern of aerobic granular sludge treating hypersaline wastewater. Bioresour. Technol. 229, 152-159. https://doi.org/ 10.1016/j.biortech.2017.01.024.

Cristovão, R.O., Botelho, C.M., Martins, R.J.E., Loureiro, J.M., Boaventura, R.A.R., 2015. Fish canning industry wastewater treatment for water reuse - a case study. J. Clean Prod. 87, 603-612. https://doi.org/10.1016/j.jclepro.2014.10.076.

de Kreuk, M., Heijnen, J.J., van Loosdrecht, M.C.M., 2005. Simultaneous COD, nitrogen, and phosphate removal by aerobic granular sludge. Biotechnol. Bioeng. 90, 761-769. https://doi.org/10.1002/bit.20470.

de Kreuk, M.K., Kishida, N., Tsuneda, S., van Loosdrecht, M.C.M., 2010. Behavior of polymeric substrates in an aerobic granular sludge system. Water Res. 44, 5929-5938. https://doi.org/10.1016/j.watres.2010.07.033.

Edgar, R.C., Haas, B.J., Clemente, J.C., Quince, C., Knight, R., 2011. UCHIME improves sensitivity and speed of chimera detection. Bioinformatics 27, 2194-2200. https://doi.org/ 10.1093/bioinformatics/btr381.
Eren, A.M., Maignien, L., Sul, W.J., Murphy, L.G., Grim, S.L., Morrison, H.G., et al., 2013. Oligotyping: differentiating between closely related microbial taxa using 16S rRNA gene data. Methods Ecol. Evol. 4, 1111-1119. https://doi.org/10.1111/2041-210x.12114

Eren, A.M., Morrison, H.G., Lescault, P.J., Reveillaud, J., Vineis, J.H., Sogin, M.L., 2015. Minimum entropy decomposition: unsupervised oligotyping for sensitive partitioning of high-throughput marker gene sequences. ISME J. 9, 968-979. https://doi.org/ 10.1038/ismej.2014.195.

Guo, H.X., van Lier, J.B., de Kreuk, M., 2020. Digestibility of waste aerobic granular sludge from a full-scale municipal wastewater treatment system. Water Res. 173. https:// doi.org/10.1016/j.watres.2020.115617.

Hamza, R.A., Zaghloul, M.S., Lorhemen, O.T., Sheng, Z., Tay, J.H., 2019. Optimization of organics to nutrients (COD:N:P) ratio for aerobic granular sludge treating high-strength organic wastewater. Sci. Total Environ. 650, 3168-3179. https://doi.org/10.1016/j. scitotenv.2018.10.026.

He, Q.L., Song, J.Y., Zhang, W., Gao, S.X., Wang, H.Y., Yu, J., 2020. Enhanced simultaneous nitrification, denitrification and phosphorus removal through mixed carbon source by aerobic granular sludge. J. Hazard. Mater. 382. https://doi.org/ 10.1016/j.jhazmat.2019.121043.

Hugo C., Bernardet J.-F., Nicholson A., Kämpfer P., 2020. Chryseobacterium. In: Whitman WB Rainey F, Kämpfer P, Trujillo M, Chun J, DeVos P, et al., editors. Bergey's Manual of Systematics of Archaea and Bacteria, pp. 1-107. https://doi.org/10.1002/9781118960608. gbm00301.pub2.

Jiang, Y., Sorokin, D., Kleerebezem, R., Muyzer, G., van Loosdrecht, M., 2011. Plasticicumulans acidivorans gen. nov., sp. nov., a polyhydroxyalkanoateaccumulating gammaproteobacterium from a sequencing-batch bioreactor. Int J. Syst. Evol. Microbiol. 61, 2314-2319. https://doi.org/10.1099/ijs.0.021410-0.

Kämpfer, P., Weltin, D., Hoffmeister, D., Dott, W., 1995. Growth requiremets of filamentous bacteria isolated from bulking and scumming sludge. Water Res. 29, 1585-1588. https://doi.org/10.1016/0043-1354(94)00275-c.

Kisand, V., Cuadros, R., Wikner, J., 2002. Phylogeny of culturable estuarine bacteria catabolizing riverine organic matter in the northern Baltic Sea. Appl. Environ. Microbiol. 68, 379-388. https://doi.org/10.1128/aem.68.1.379-388.2002.

Layer, M., Adler, A., Reynaert, E., Hernandez, A., Pagni, M., Morgenroth, E., et al., 2019. Organic substrate diffusibility governs microbial community composition, nutrient removal performance and kinetics of granulation of aerobic granular sludge. Water Res. X 4. https://doi.org/10.1016/j.wroa.2019.100033.

Li, S., Li, D., Wang, Y., Zeng, H., Yuan, Y., Zhang, J., 2020. Startup and stable operation of advanced continuous flow reactor and the changes of microbial communities in aerobic granular sludge. Chemosphere 243. https://doi.org/10.1016/j. chemosphere.2019.125434.

Liu, Y.W., Ngo, H.H., Guo, W.S., Peng, L., Wang, D.B., Ni, B.J., 2019. The roles of free ammonia (FA) in biological wastewater treatment processes: a review. Environ. Int. 123, 10-19. https://doi.org/10.1016/j.envint.2018.11.039.

Marques, R., Santos, J., Nguyen, H., Carvalho, G., Noronha, J.P., Halkjær Nielsen, P., et al, 2017. Metabolism and ecological niche of Tetrasphaera and Ca. Accumulibacter in enhanced biological phosphorus removal. Water Res. 122, 159-171. https://doi.org/ 10.1016/j.watres.2017.04.072

McBride, M.J., Liu, W., Lu, X., Zhu, Y., Zhang, W., 2014. The family Cytophagaceae. In: DEF, Rosenberg E., Lory, S., Stackebrandt, E., Thompson, F. (Eds.), The Prokaryotes. Springer, Berlin, pp. 577-593 https://doi.org/10.1007/978-3-642-38954-2_382.

Meinhold, J., Arnold, E., Isaacs, S., 1999. Effect of nitrite on anoxic phosphate uptake in biological phosphorus removal activated sludge. Water Res. 33, 1871-1883. https://doi. org/10.1016/S0043-1354(98)00411-4.

Moura, L.L., Duarte, K.L.S., Santiago, E.P., Mahler, C.F., Bassin, J.P., 2018. Strategies to reestablish stable granulation after filamentous outgrowth: insights from lab-scale experiments. Process Saf. Environ. Prot. 117, 606-615. https://doi.org/10.1016/j. psep.2018.06.005.

Oshiki, M., Onuki, M., Satoh, H., Mino, T., 2008. PHA-accumulating microorganisms in fullscale wastewater treatment plants. Water Sci. Technol. 58, 13-20. https://doi.org/ 10.2166/wst.2008.652.

Parte, A., Krieg, N.R., Ludwig, W., Whitman, W.B., Hedlund, B.P., Paster, B.J., et al., 2010. 2010. In. 4. Springer, USA https://doi.org/10.1007/978-0-387-68572-4.

Pishgar, R., Dominic, J.A., Sheng, Z.Y., Tay, J.H., 2019. Influence of operation mode and wastewater strength on aerobic granulation at pilot scale: startup period, granular sludge characteristics, and effluent quality. Water Res. 160, 81-96. https://doi.org/ 10.1016/j.watres.2019.05.026.

Pronk, M., Bassin, J.P., de Kreuk, M.K., Kleerebezem, R., van Loosdrecht, M.C., 2014. Evaluating the main and side effects of high salinity on aerobic granular sludge. Appl. Microbiol. Biotechnol. 98, 1339-1348. https://doi.org/10.1007/s00253-013-4912-z.

Qian, W.T., Peng, Y.Z., Li, X.Y., Zhang, Q., Ma, B., 2017. The inhibitory effects of free ammonia on ammonia oxidizing bacteria and nitrite oxidizing bacteria under anaerobic condition. Bioresour. Technol. 243, 1247-1250. https://doi.org/10.1016/j.biortech.2017.07.119.

Ramos, C., Amorim, C.L., Mesquita, D.P., Ferreira, E.C., Carrera, J., Castro, P.M.L., 2017. Simultaneous partial nitrification and 2-fluorophenol biodegradation with aerobic granular biomass: reactor performance and microbial communities. Bioresour. Technol. 238, 232-240. https://doi.org/10.1016/j.biortech.2017.03.173.

Rognes, T., Flouri, T., Nichols, B., Quince, C., Mahe, F., 2016. VSEARCH: a versatile open source tool for metagenomics. Peerj. 4. https://doi.org/10.7717/peerj.2584.

Rollemberg, S.L.D., Barros, A.R.M., Firmino, P.I.M., dos Santos, A.B., 2018. Aerobic granular sludge: cultivation parameters and removal mechanisms. Bioresour. Technol. 270 678-688. https://doi.org/10.1016/j.biortech.2018.08.130.

Saito, T., Brdjanovic, D., van Loosdrecht, M.C.M., 2004. Effect of nitrite on phosphate uptake by phosphate accumulating organisms. Water Res. 38, 3760-3768. https://doi org/10.1016/j.watres.2004.05.023. 
Świątczak, P., Cydzik-Kwiatkowska, A., 2018. Performance and microbial characteristics of biomass in a full-scale aerobic granular sludge wastewater treatment plant. Environ. Sci. Pollut. Res. 25, 1655-1669. https://doi.org/10.1007/s11356-017-0615-9.

Szabó, E., Liebana, R., Hermansson, M., Modin, O., Persson, F., Wilen, B.M., 2017. Microbial population dynamics and ecosystem functions of anoxic/aerobic granular sludge in sequencing batch reactors operated at different organic loading rates. Front. Microbiol. 8, 770. https://doi.org/10.3389/fmicb.2017.00770.

Tang, H.L., Chen, H.P., 2015. Nitrification at full-scale municipal wastewater treatment plants: evaluation of inhibition and bioaugmentation of nitrifiers. Bioresour. Technol. 190, 76-81. https://doi.org/10.1016/j.biortech.2015.04.063.

Turner, S., Pryer, K.M., Miao, V.P.W., Palmer, J.D., 1999. Investigating deep phylogenetic relationships among cyanobacteria and plastids by small submit rRNA sequence analysis. J. Eukaryot. Microbiol. 46, 327-338. https://doi.org/10.1111/j.1550-7408.1999. tb04612.x.

Weissbrodt, D.G., Shani, N. Holliger, C. 2014. Linking bacterial population dynamics and nutrient removal in the granular sludge biofilm ecosystem engineered for wastewater treatment. FEMS Microbiol. Ecol. 88, 579-595. https://doi.org/10.1111/15746941.12326.

Winkler, M.K.H., Meunier, C., Henriet, O., Mahillon, J., Suarez-Ojeda, M.E., Del Moro, G., et al., 2018. An integrative review of granular sludge for the biological removal of nutrients and recalcitrant organic matter from wastewater. Chem. Eng. J. 336, 489-502. https://doi.org/10.1016/j.cej.2017.12.026.

Xia, J.T., Ye, L., Ren, H.Q., Zhang, X.X., 2018. Microbial community structure and function in aerobic granular sludge. Appl. Microbiol. Biotechnol. 102, 3967-3979. https://doi.org/ 10.1007/s00253-018-8905-9.

Zhang, H., 2003. Gemmatimonas aurantiaca gen. nov., sp. nov., a Gram-negative, aerobic polyphosphate-accumulating micro-organism, the first cultured representative of the new bacterial phylum Gemmatimonadetes phyl. nov. Int. J. Syst. Evol. Microbiol. 53, 1155-1163. https://doi.org/10.1099/ijs.0.02520-0.

Zhang, L., Long, B., Wu, J., Cheng, Y., Zhang, B., Zeng, Y., et al., 2019. Evolution of microbial community during dry storage and recovery of aerobic granular sludge. Heliyon 5 , e03023. https://doi.org/10.1016/j.heliyon.2019.e03023.

Zheng, X., Sun, P., Lou, J., Cai, J., Song, Y., Yu, S., et al., 2013. Inhibition of free ammonia to the granule-based enhanced biological phosphorus removal system and the recoverability. Bioresour. Technol. 148, 343-351. https://doi.org/10.1016/j.biortech.2013.08.100.

Zhou, D., Niu, S., Xiong, Y., Yang, Y., Dong, S., 2014. Microbial selection pressure is not a prerequisite for granulation: dynamic granulation and microbial community study in a complete mixing bioreactor. Bioresour. Technol. 161, 102:108. https://doi.org/ 10.1016/j.biortech.2014.03.001. 